\title{
Thermal modelling and simulation of a laboratory building for cooling energy consumption
}

\author{
Fakher Eldin M. Suliman* and Elfatih A. Elsheikh \\ Department of Electrical Engineering, College of Engineering, King Khalid University, Abha, 61421, Saudi Arabia \\ *Corresponding Author:fmsuliman@kku.edu.sa
}

Submitted : 01/03/2020

Revised :02/12/2020

Accepted : 14/12/2020

\begin{abstract}
The main objective of this study is to identify and calculate the necessary variables for a building that can be used as input data in energy simulation tools and to determine the cooling energy consumption buildings and to examine the influence of applying energy rationalization measures. Based on that, we developed, applied, and validated a Simulink-based energy demand model of a governmental building to quantify the amount of cooling energy consumption in a case study environment. The model includes an air conditioner (plant model), controlled by a thermostat (controller model), to cool the laboratory building (environment model) to the desired temperature. The processes used here to construct the model layout and algorithm design can be extended to accommodate other multipart models or different construction sectors.
\end{abstract}

Keywords: Energy consumption; Buildings thermal behavior; Plant model; Environment model; Controller model; Indoor/outdoor temperature.

\section{INTRODUCTION}

Buildings play a pivotal role and are integral to all sectors of the economy, such as residential, industry, and manufacturing, and the services sector (tourism, financial services, schools, universities, and hospitals). Buildings use approximately 40 per cent of energy demand in many countries, and 60 per cent of these construction needs are used for heating and cooling purposes (Kaynakli, 2012). Many factors contribute to this high shift in the demand for electricity in buildings. Table 1 lists these factors.

Due to its geographical position, the temperature in Saudi Arabia is very high most of the year. In addition, most of the building structures in Saudi Arabia are made of concrete or concrete masonry units (CMUs). There are 2886132 concrete and CMU houses in the residential sector alone, which is about 84.4 per cent of the overall number of houses (Electricity Energy Statistics-2018). Therefore, usage and necessity of air conditioning is scientifically high. Additionally, more than 2/3 of the buildings in Saudi Arabia do not apply thermal insulation, which is essential to reduce thermal losses and maintain the desired comfort environment within the building and hence reduce the total cooling energy consumed (Annual Report-2018). According to the General Statistics Authority in Saudi Arabia, more than 99.19 per cent of buildings are linked to the public power grid. 
Table 1. Factors affecting energy consumption in buildings.

\begin{tabular}{ll}
\hline Factor base & Factor details \\
\hline Occupants & Presence, age, gender, and daily activities \\
\hline Appliances & Ownership, operation, and specification \\
\hline Climate & Location, season, day time, and meteorological data \\
\hline Building & Size, materials used, insulation, and orientation \\
\hline
\end{tabular}

Buildings in Saudi Arabia are marked by a severe excess of electrical consumption, as they consume $80 \%$ of the total electricity generated. The consumption of energy for air conditioning alone accounts for 50 per cent of the overall energy used by buildings. The building's sectors percentage energy consumption in Saudi Arabia is distributed as shown in Figure 1. Generally, these buildings are distinguished by a severe excess of electrical usage in lighting, air conditioning, heating, and to operate other devices. Figure 2 illustrates the percentage of each energy use type in Saudi Arabia.

The building sector has the most massive potential for cost-effective improvement in energy efficiency and emissions reductions (Krarti et al. 2019). Additionally, focusing on buildings brings significant social co-benefits, such as (Dubey and Dodonov, 2018):

- Increasing energy security

- Expanding entrepreneurial opportunities

- $\quad$ Reducing energy poverty

- Increasing access to energy services

- Improving both indoor and outdoor air quality

- Increasing comfort and living standards

- $\quad$ Reducing in $\mathrm{CO} 2$ emissions

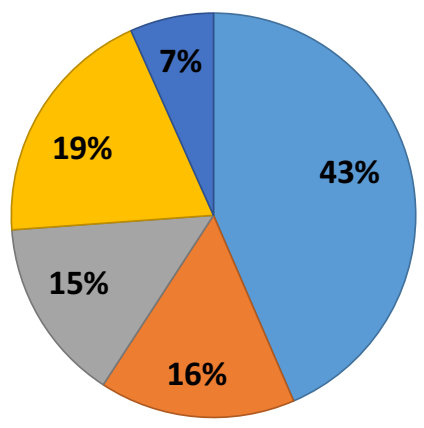

\section{$\square$ Residential \\ Commercial \\ Govermental \\ $\square$ Industrial}

$\square$ Others

Figure 1. Building's sectors percentage energy consumption in Saudi Arabia. 


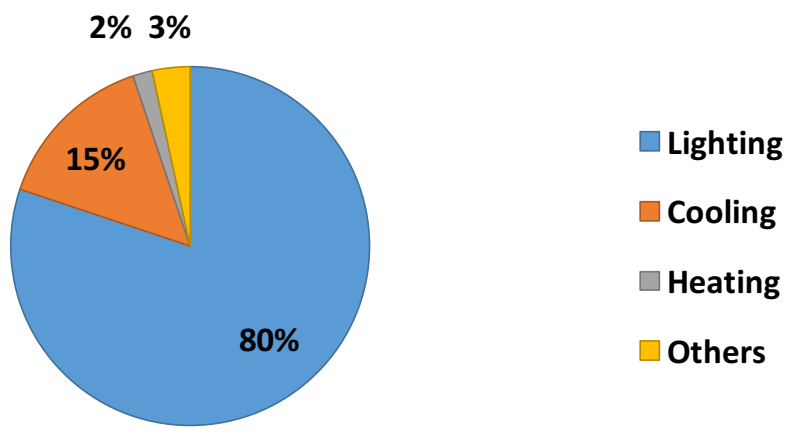

Figure 2. The percentage of each energy use type in Saudi Arabia.

To enhance energy efficiency in buildings, national public policy should include a variety of mechanisms which are meant to encourage and stimulate investment in energy efficiency. These mechanisms may consist of mandatory standards, cash and tax incentives, and consumer information programs. The Saudi government recently ordered entities to reduce the use of energy in existing government buildings and to use thermal insulation for new buildings. The Minister of Water and Electricity also demanded no construction should be linked to the public electricity network unless the owner has applied to thermal insulation (Annual Report-2018). Three categories of measures which may be taken to rationalize buildings energy consumption for cooling are recommended in Table 2 .

This paper concentrates on the factors which affect energy consumpsion in buildings. The study takes into account the local conditions of the building and all the internal heat load involved. The main objective of this study is to identify and calculate the necessary variables for a building that can be used as input data in energy simulation tools. Based on that, we developed, applied, and validated a Simulink-based energy demand model of a governmental building to quantify the amount of cooling energy consumption in a case study environment. This approach is considered the novelty of this work. The study analysis, which is based on empirical data, can present pertinent findings for cases in a similar atmosphere. It may also assist stakeholders in understanding energy rationalization potential in a variety of roles.

Table 2. Measures to rationalize cooling energy in buildings.

\begin{tabular}{|c|c|}
\hline Recommendation category & Measures to reduce cooling energy consumption \\
\hline Thermal behavior enhancement & $\begin{array}{l}\text { - } \quad \text { Apply periodic maintenance } \\
\text { - } \quad \text { Avoid cold air leakage } \\
\text { - } \quad \text { Ape materials with better thermal properties } \\
\text { - } \quad \text { Replace single glazed with double/triple glazed }\end{array}$ \\
\hline $\begin{array}{l}\text { Measures concerning the } \\
\text { appliances }\end{array}$ & $\begin{array}{l}\text { Use energy-efficient appliances } \\
\text { - } \quad \text { Choose a suitable AC to fit the building size } \\
\text { - } \quad \text { Select the thermostat set point between } 23-25 \mathrm{C}\end{array}$ \\
\hline
\end{tabular}




\section{Building automation} approaches
Apply automation for the new buildings

Use AC with smart thermostat and timers

Use smart occupant detectors

Control each part of the building separately

Install smart blinds and smart lightning

\section{MODELLING BUILDING COOLING SYSTEM}

Modelling a building thermal behavior provides necessary data for energy consumption that can be used for placing future energy use measures. It also reflects how the building complies with the required standards and specifications. Managing energy in buildings has been a research focus recently. It deals with energy demand as an adjustable resource to improve the electric power system performance and to reduce the cost.

Yashen (2012) attempted the development of a model which describes the thermal dynamics of a single room that is suitable for intelligent control. Yashen compared various model structures and found that a second order model using electrical analogy is a good choice. The effect of open door on the model is also discussed, and a modified model is developed. The author collected experimental data from Pugh Hall on University of Florida for model calibration and validation. Experiments to analyze the thermal behavior of the wall materials were performed and reported in (Wonorahardjo et al., 2019). Experiments and simulations were carried out on the four most popular building materials in tropical areas: brick, aerated concrete, wood with glass-wool insulation, and glass fibrereinforced concrete with glass-wool insulation to examine their effect on the heat island intensity (HII). The thermal behavior of a school building both in stationary and dynamic conditions was simulated in (Carlinia et al., 2015) to investigate how the building energy efficiency can be improved while maintaining occupants' thermal comfort. The paper presents the case study of the School of the State Forestry Corp in Sabaudia (Italy). The results show that the thicknesses of insulating material do not represent an advisable retrofitting in summer. A new simulation program for estimating energy use of residential buildings according to the European standard EN832 was presented in (Sjösten et ai., 2013). In this paper authors introduce a computer simulation tool called TEKLA, which is developed using MATLAB 6.2 to obtain such analyses. The tool evaluation was obtained based on data from a monitored inhabited single-family building located in northern Sweden. A simulation tool for analyzing the thermodynamic behavior of multi-room residential buildings using multi-physics description software Simscape was developed in (Lapusan et al., 2015). The developed model can be used for testing and optimization experiments in the design phase of building heating control systems. The proposed approach is tested by implementing a four-room building model Matlab/Simulink. The advantages and disadvantages of available methods as well as the input parameters used for modelling buildings energy performance were reviewed in (Hrvoje and Mihaela, 2017). Some of the methods mentioned in this paper are developed by employing data sets of buildings which have already undergone an energy certification procedure. Amara et al. (2015) propose a detailed review and simulation of three main thermal building models. The first is based on physical and basic principle modeling (white-box). The second is the statistical models (black-box) used for prediction of energy consumption and heating/ cooling demands. Finally, the third is a hybrid method (grey-box), which uses both physical and statistical modeling techniques. They concluded that the grey-box is the most effective model for management of buildings energy consumption. The most modern approaches based on physical, statistical, and hybrid techniques used to model and predict energy consumption and heating/cooling demand in buildings are also reviewed in (Foucquier et al., 2013). The preparation of thermal separation and air cavities to enhance the thermal characteristics of CMU building blocks was investigated in (Mooneghi et al., 2015). The overall thermal performance of the CMU can be improved by proper arrangement of thermal insulation and air holes and appropriate sizing of these insulators. Results demonstrate that decreasing the thermal bridging effect 
improves the thermal performance of the blocks. Also, it is shown that thermal efficient blocks are most effective for cold climates. Mohelníková et al. (2020) carried a study to evaluate building energy performance in an indoor classroom environment. The evaluation was based on data analysis of energy audits. The goal was aimed at assessment of the school building envelopes and their influence on energy consumption. A computer modelling investigation by using Thermal Analysis Software (TAS) was done in (Shohan et al., 2020) to assess thermal and energy performance in Mosque buildings in the mountainous and semi-arid climate of Abha City. The outcome showed some discomfort due to heat gain in summer and heat loss in winter which occur because of the poor quality of the investigated Mosque buildings. Bataineh and Alrabee (2018) investigated impact of energy retrofit programs for the existing residential buildings under the typical Jordanian weather. Several building types located in Jordan were considered as case study. Three levels of energy retrofit programs have been proposed and parametric analyses have been performed to determine the impact of each energy efficiency measure on the energy performance of residential buildings.

\section{MATERIALS AND METHODS}

The modelling of the cooling system of any building should address both the goal and components of the modeling. The main objective for modeling the cooling system of a building is to detect how the indoor temperature of the building is affected by changing outdoor temperature and other various parameters. The model explains the laboratory building cooling structure and addresses its association with the building's thermal gain and internal heat losses.

\section{Laboratory Geographical Location}

The laboratory building under consideration is located at King khalid University in Abha, Saudi Arabia. Abha is is situated 7,450 feet above sea level at Latitude: $18.246469^{\circ}$ and Longitude: $42.511724^{\circ}$. The weather in Abha varies from hot and semi-arid lengthy summers to cool and mostly clear short winters. The annual average temperature ranges from $7.2{ }^{\circ} \mathrm{C}$ to $28.3{ }^{\circ} \mathrm{C}$ (Long-term Weather Forecast, 2019).

\section{Laboratory Characteristics}

The physical characteristics and the thermal load components of the laboratory building are summarized in Table 3. The laboratories are placed at the corner of the second floor of a two-floor workshops and laboratory building. The building plan of the three laboratories is illustrated in Figure 3. The building atmosphere is treated as a sink of limitless thermal capacity with the outdoor temperature changing in real-time. The On / Off switch controller periodically controls the building temperature and, subject to the variance between the established temperature and the enclosed room temperature, switches on or off the air conditioner. It consists of three main components: air conditioner as the gain source, an on/off switch as the controller and the laboratory rooms as the thermal zone. 


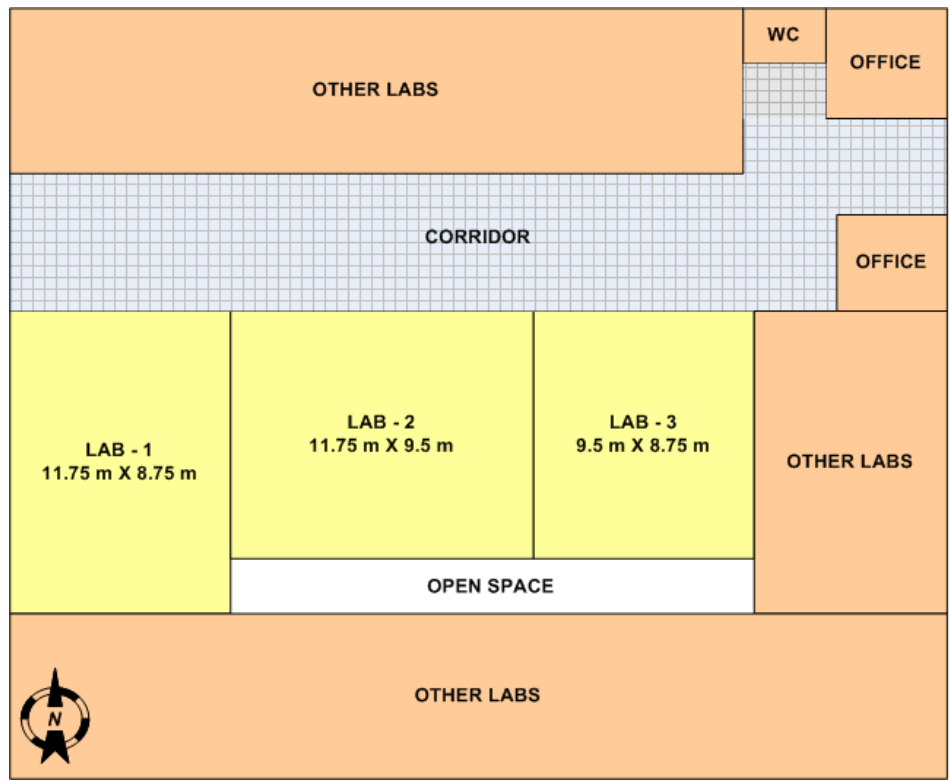

Figure 3. The laboratory building plan.

Table 3. The characteristics of the laboratory buildings.

Element

Buildings envelope

\section{Characteristics}

Concrete roof slab and floor slab

The area of roof and floor $=297.5625 \mathrm{~m}^{2}$

Seven concrete masonry unit (CMU) internal walls

The area of internal walls $=266 \mathrm{~m}^{2}$

3.3 CMU external walls

The area of external walls $=138 \mathrm{~m}^{2}$

Three wood doors. The area of doors $=6 \mathrm{~m}^{2}$

Six glass windows. The area of windows $=7.5 \mathrm{~m}^{2}$

Depth of wall $=0.21 \mathrm{~m}$, Depth of door $=0.04 \mathrm{~m}$, and Depth of window $=0.003 \mathrm{~m}$

\section{Cooling}

Six wall-mounted high-pressure exhaust fans

Eight wall-Mounted TRANE type air condintioners 
Ten COMLAB3 experiment kits (20 w),

Ten DELL INSPIRON N5110 laptops (65 w)

Twelve DELL OPTIPLEX 790 desktop computers (240 w)

Equipment

Five Lab-VOLT DC Motor/ Generator, five Squirrel Cage Induction

Motor, five 3-Phase Wound Rotor Induction Motor, or five Universal

Motor (175 w)

Six LUCAS NULLE Unitrain component boards

Six Measurement Technology kits $(50 \mathrm{w})$

Occupancy Thirty five persons per session

Monthly working hours $24 \mathrm{~h}$

\section{Thermal Behavior Calculations}

The thermal behavior/heating load of the laboratory building is defined based on the following components:

- $\quad$ The outdoor temperature $\left(T_{\text {out }}\right)$

- The indoor temperature $\left(T_{\text {room }}\right)$

- The involved thermal zones

- $\quad$ The building thermal gain $\left(Q_{g}\right)$

- The building thermal loss $\left(Q_{l}\right)$ including the energy associated with hot air produced by lightning $\left(T_{l}\right)$, occupants $\left(T_{o c}\right)$, and equipment $\left(T_{e}\right)$

These components can be related using differential equations considering the laboratory room temperature as the only state variable. Heat loss is obtained from the sum of the heat loss through the individual zones. Cold energy loss from the room is relative to the temperature variance between the indoor and outdoor temperature and is caused by:

- $\quad$ Losses through the walls, roof, floor, door, and windows (conduction)

- Students conducting experiments and their supervisors (occupants)

- Electrical devices operated during experiments in the building (equipment)

The total heat loss is the summation of these loss components which is given by:

$$
\mathrm{Q}_{\text {Total }}=\mathrm{Q}_{\text {Conductive }}+\mathrm{Q}_{\text {Occupants }}+\mathrm{Q}_{\text {Equipments }}
$$

The following subsections explain the details of these components.

\section{Cold Gain}

The thermal gain in the room is by convection of cooled air from the AC. The AC temperature is constant at $T_{A C}$.

The coold airflow into the building is stated by: 


$$
\frac{d Q}{d t}=\left(T_{A C}-T_{\text {room }}\right) \times M d o t \times c
$$

where

$\frac{d Q}{d t}$ is the cold airflow from the AC into the Laboratory
$T_{A C}$ is the temperature of cold air from AC

$T_{\text {room }}$ is the current room temperature

$M d o t$ air mass flow rate through AC

$c$ is the heat capacity of air at constant pressure.

\section{Heat Loss}

The overall heat loss of the building is the summation of the heat losses calculated for these different causes. The conductive losses encountered through the building envelope is calculated by finding the heat transfer coefficient (U) for each material used in the envelope. The conductive loss formula used is

$$
Q=U \times A \times \Delta T
$$

where

$\mathrm{Q}$ is the conductive loss thru the material

$\mathrm{U}$ is the heat transfer coefficient of the material

$\Delta T$ is the outdoor and indoor temperature difference. formula:

Following Suszanowicz (2017), the internal heat loss of the lighting system is determined based on the following

$$
Q_{H, o}=A_{f} \times E_{v} \times \eta^{-1} \times H_{e} \times t_{o}[\mathrm{kWh} / \mathrm{yr}]
$$

where

$Q_{H, o}$ is the internal heat gain from lighting system $[\mathrm{kWh} / \mathrm{yr}]$

$A_{f}$ is the floor area $\left[\mathrm{m}^{2}\right]$

$E_{v}$ is the illuminance [1x]

$\eta$ is the luminous efficacy $[1 \mathrm{~m} / \mathrm{W}]$

$H_{e}$ is the heat emission coefficient

$t_{o}$ is the annual light system operating hours [kh/yrs].

This formula is also used to determine the heat losses due to occupants and equipment.

The internal heat loss of occupants is determined based on their metabolic rates. Each occupant in the laboratory room is assumed to produce about 1 met ( 1 unit of metabolic rate) of waste heat. Because occupants heat interchange with the environment is mainly through the skin, the met unit is defined in terms of both heat energy and surface area $(1 \mathrm{met}=58.2 \mathrm{w} / \mathrm{m} 2$ (SI units) $=18.4 \mathrm{Btu} / \mathrm{h} / \mathrm{ft} 2)$. Using the Du Bois formula (Body Surface Area, 2019), the average body surface area of students in KKU is estimated as $1.3 \mathrm{~m}^{2}$, and hence the heat produced by each is assumed to be about 75.66 watts (ANSI/ASHRAE 55-2017). 
The internal heat loss of equipment includes lightning of the room, laptops, and experimental kits used and are determined based on their respective specification documents and datasheets. For this modelling study, both occupant and equipment heat losses calculations assumed they are florescent light bulbs with equivalent wattage.

\section{Changing Laboratory Temperature}

The rate of change in the laboratory room temperature can be obtained by

$$
\begin{aligned}
& \left(\frac{d Q}{d t}\right)_{\text {losses }}=\frac{T_{\text {out }}-T_{\text {room }}}{R_{\text {eq }}} \\
& \frac{d T_{\text {room }}}{d t}=\frac{1}{M_{\text {air }} \times c}\left(\frac{d Q_{\text {losses }}}{d t}-\frac{d Q_{A C}}{d t}\right)
\end{aligned}
$$

where $R_{e q}$ is the equivalent thermal resistance of the building

\section{Model Parameterization}

Most of the required parameters are collected from related information published in the literature (ANSI/ASHRAE 55-2017) and (ASHRAE Handbook-Fundamentals. 2017). The building materials and energy cost tariffs are from reports issued by the governmental authority in Saudi Arabia (General Authority for Statistics, 2018). The specifications for the exhaust fans, the AC units, the lambs, the experimental equipment, and the computers used in the laboratory are collected from their respective manufacturer documentation (LISIN HighPressure Exhaust Fan Model DVN-101 / DVN-121 Catalogue, Residential Split Systems From 0.6 to 5 T. R., Philips Fluorescent Lamp Data Sheet, Com3lab: The Compact Electronics Laboratory, DELL OPTIPLEX 790 Technical Guide, and DELL INSPIRON N5110 Setup Guide, LAB - VOLT Company, and LUCAS NULLE Company).

\section{Model Phases}

The laboratory cooling system model is organized into a ranked arrangement which corresponds to the individual components. The top-level structure is modeled with suitable elements that represent the On/Off switch, $\mathrm{AC}$, and laboratory building subsystems. The model also have interfaces for passing data between individual components.

\section{The Model}

The complete laboratory building Simulink thermal model is illustrated in Figure 4. The Desired Temperature block enables the selection of the desired room temperature. The Outdoor Temperature block provides the real outdoor temperature readings. The Air Conditioner subsystem blows cold air at a constant flow rate and a default temperature. It contains a thermostat block which allows fluctuations of a selected degree around the desired temperature and turns on or off the AC accordingly. The thermal gain and losses of the building are compared in the Laboratory Building subsystem. The Energy Consumption and Cost Calculator block evaluates the consumed cooling energy and calculates its cost using the predefined rates. 


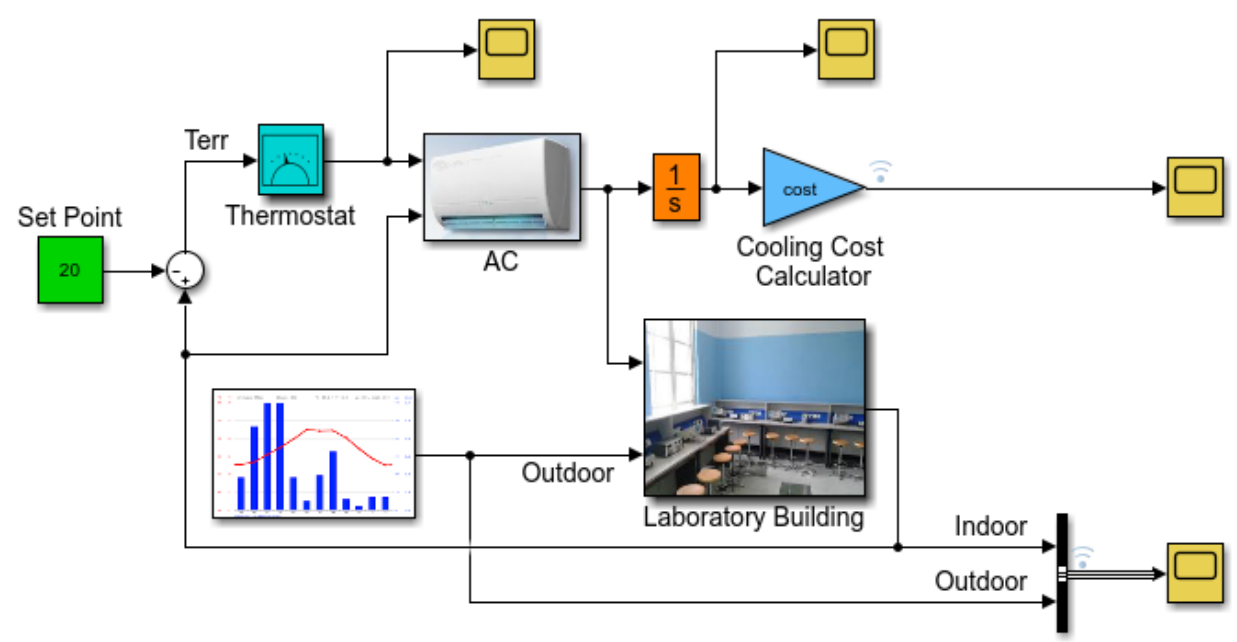

Figure 4. The laboratory Simulink thermal model.

\section{RESULTS AND DISCUSSIONS}

For the model simulation, heat losses through wind speed and through walls and floors shared between similar zones are ignored. Also, the experiment sessions per each day are assumed to be conducted symalteanously. The model has been simulated for a popular desired set point of $20^{\circ}$ C. Figure 5 presents the on/off changing states of the control signal generated from the thermostat to maneuver the air conditioner operation during the month. Figure 6 presents the energy consumed to cool the building during the test period, where it reaches a total of $5.144 \times 10^{9}$ joules/hour. In Figure 7, the indoor and outdoor temperature of the laboratory building is presented. Sometimes, the outside temperature is less than the desired inside temperature; in such cases, the indoor temperature follows the outdoor weather with a slight delay, and thermal losses work reversibly. The indoor temperature carve also reflects the fluctuations of one degree Celsius around the $20^{\circ} \mathrm{C}$ setpoint desired temperature. The monthly cost of the energy consumed to cool the building is shown in Figure 8.

Some of the measures proposed for reducing energy consumption can be applied to the laboratory building model. They can be checked individually (or collectively) to observe the effect of each (or of their combination) on the building thermal behavior. For example, the desired temperature can be set to $23^{\circ} \mathrm{C}$ as recommended by (ANSI/ASHRAE 55-2017). The model has been simulated for $23^{\circ} \mathrm{C}$ to compare the thermal behavior of the building after applying this measure. The operation signal of the air conditioner varies considerably to reach the desired temperature setpoint as illustrated in Figure 9. Figure 10 presents the energy consumed to cool the building during the test period, where it reaches a total of $3.157 \times 10^{9}$ joules/hour. In Figure 11, the indoor and outdoor temperature of the laboratory building for $23{ }^{\circ} \mathrm{C}$ is presented. The monthly cooling cost drops from 457.8 SAR to be 281 SAR, as presented in figure 12 . The accomplished monthly saving in the consumed energy and its cost is about 61.38 percent. Figure 13 illustrates a comparison between the two setpoints. 


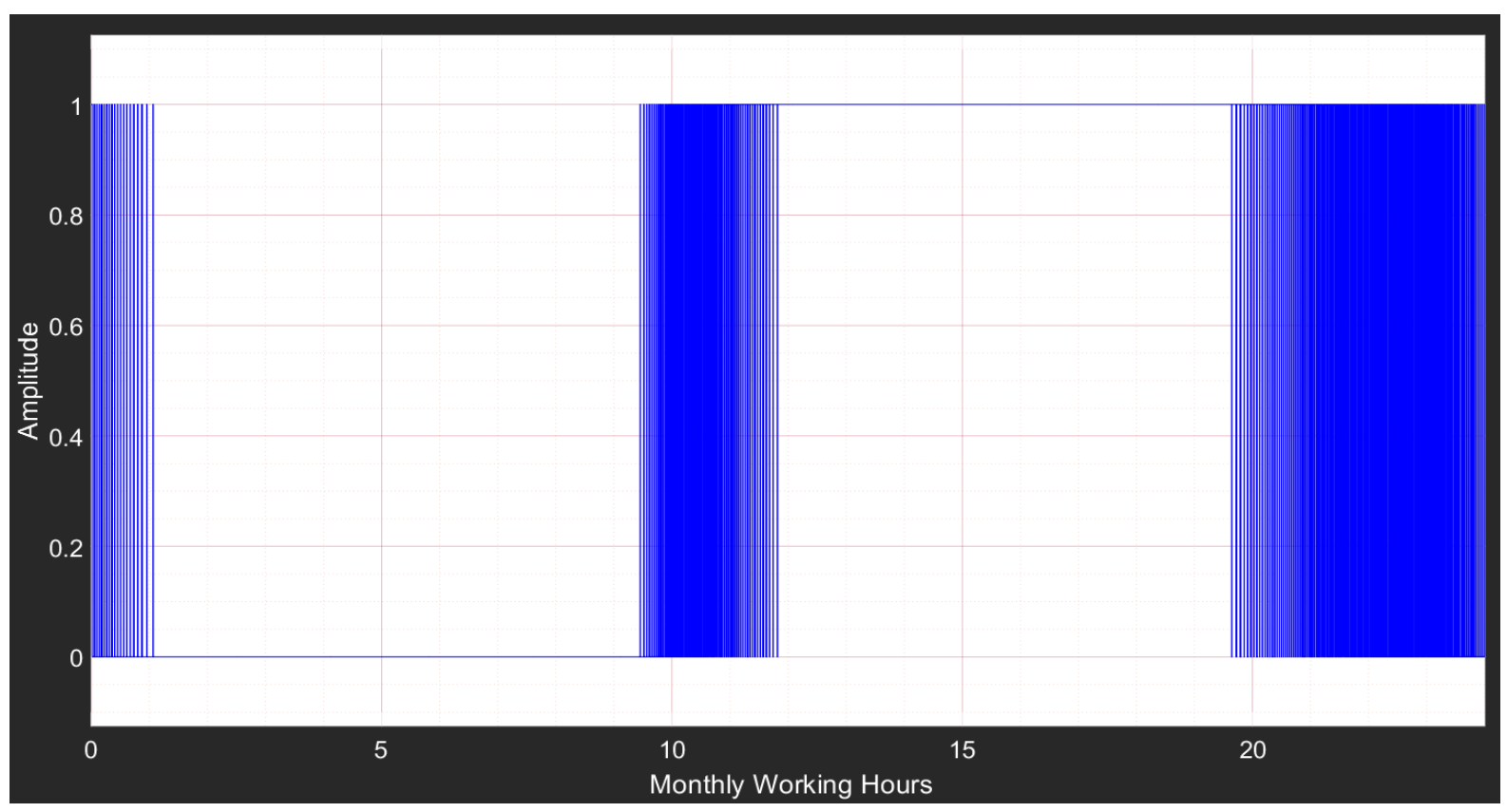

Figure 5. The control signal generated from the thermostat for $20{ }^{\circ} \mathrm{C}$ setpoint.

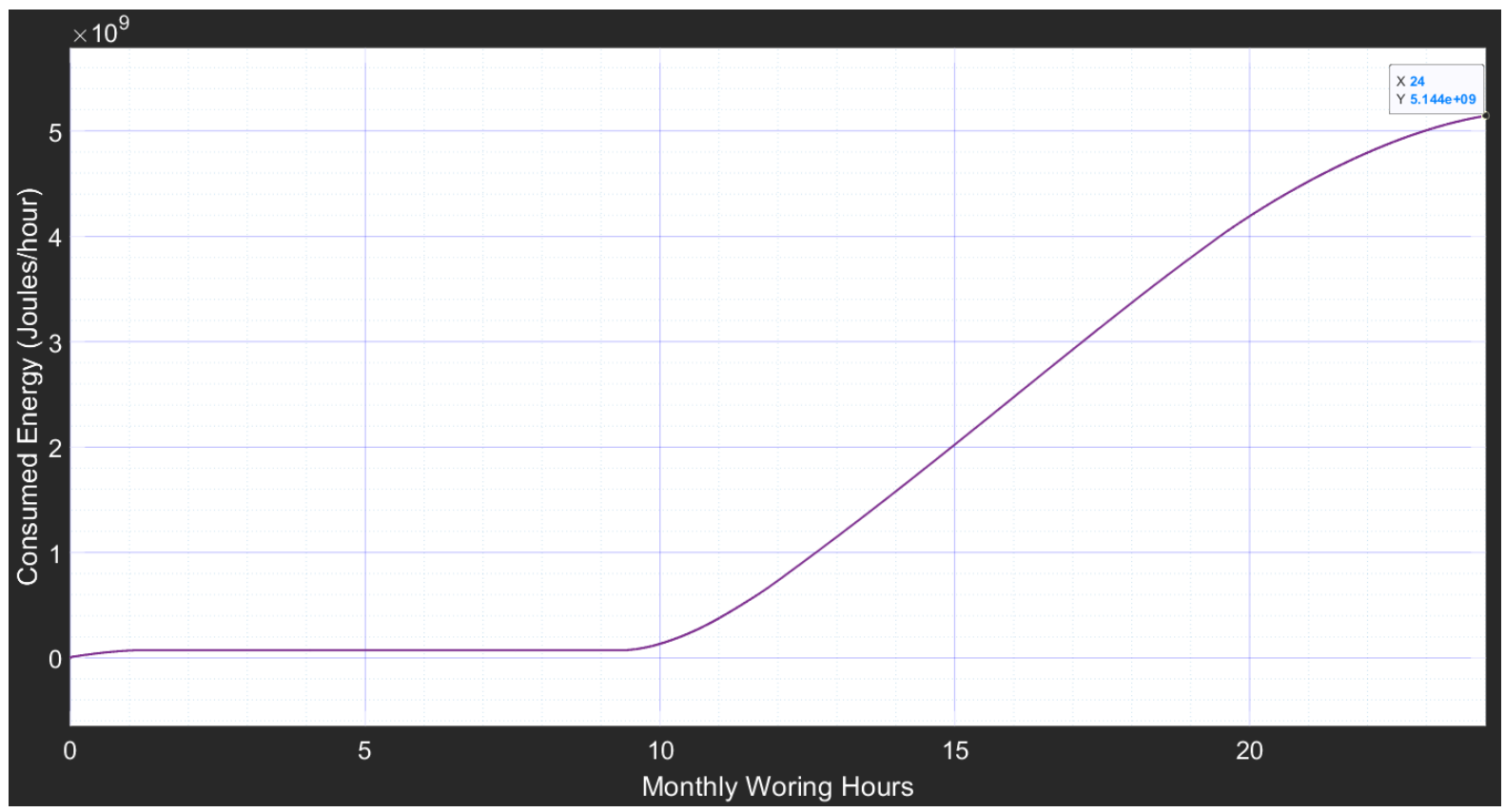

Figure 6. The monthly energy consumed to cool the building for $20^{\circ} \mathrm{C}$ setpoint. 


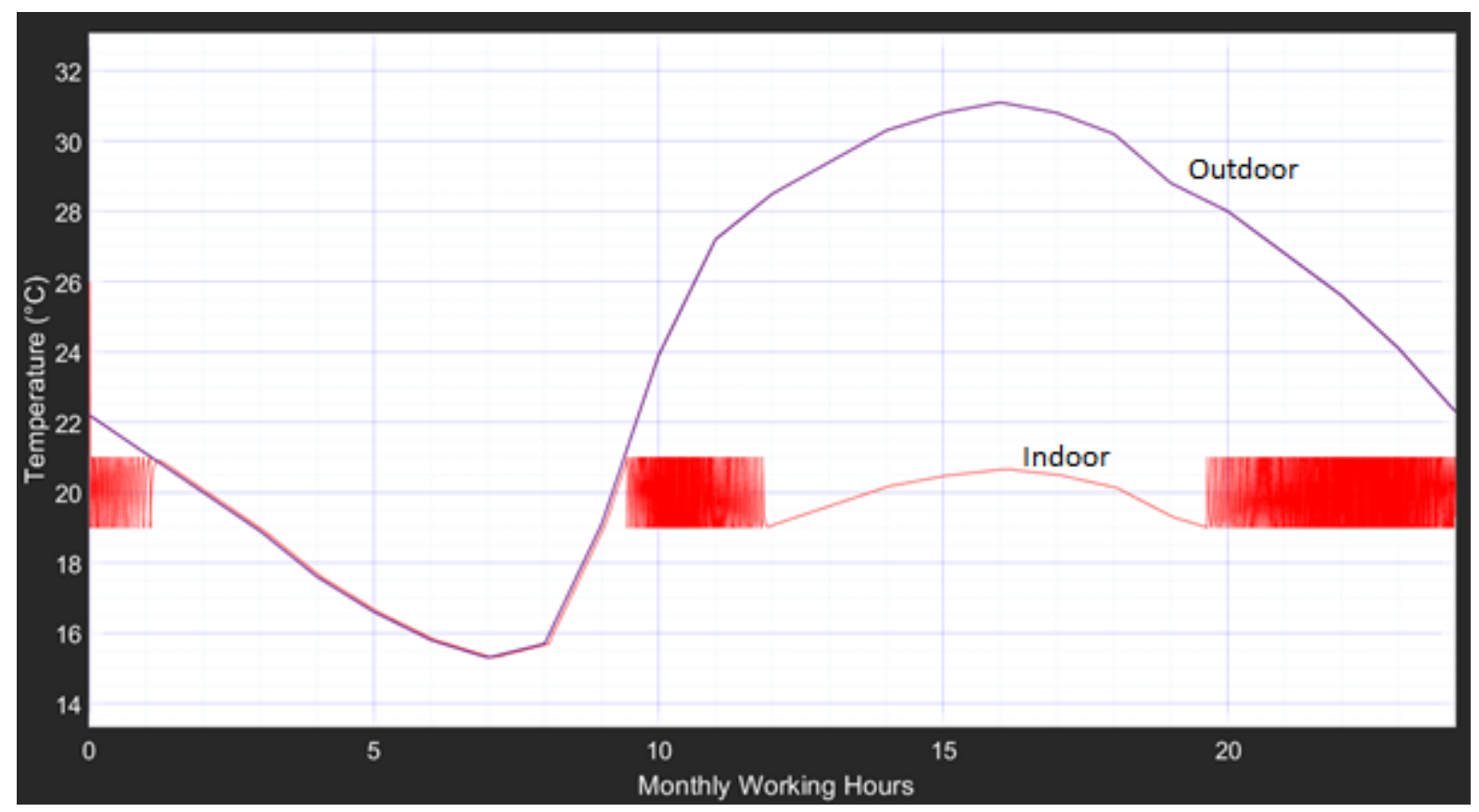

Figure 7. The indoor and outdoor temperature for $20^{\circ} \mathrm{C}$ setpoint.

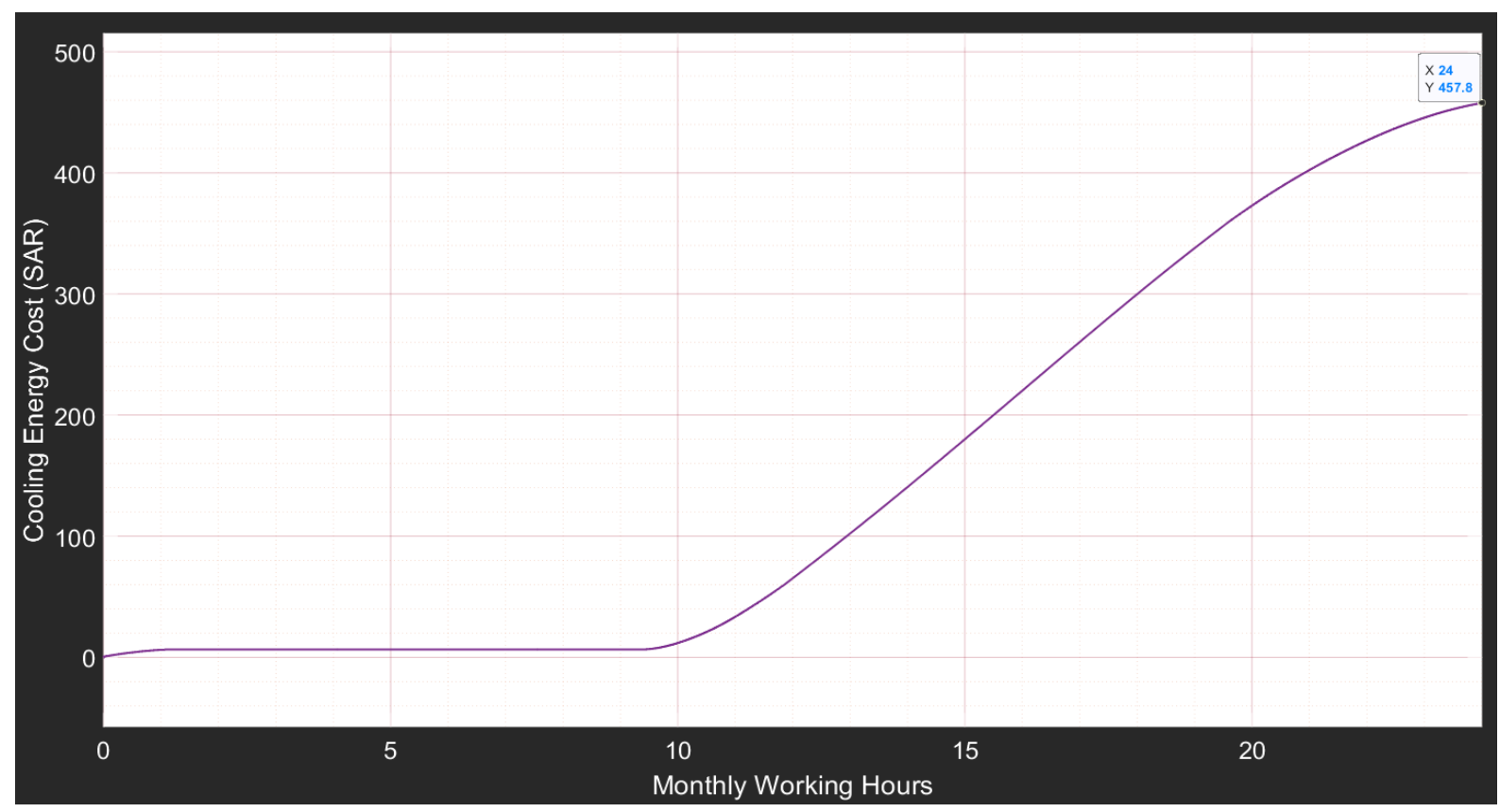

Figure 8. The monthly cost of cooling energy for $20^{\circ} \mathrm{C}$ setpoint. 


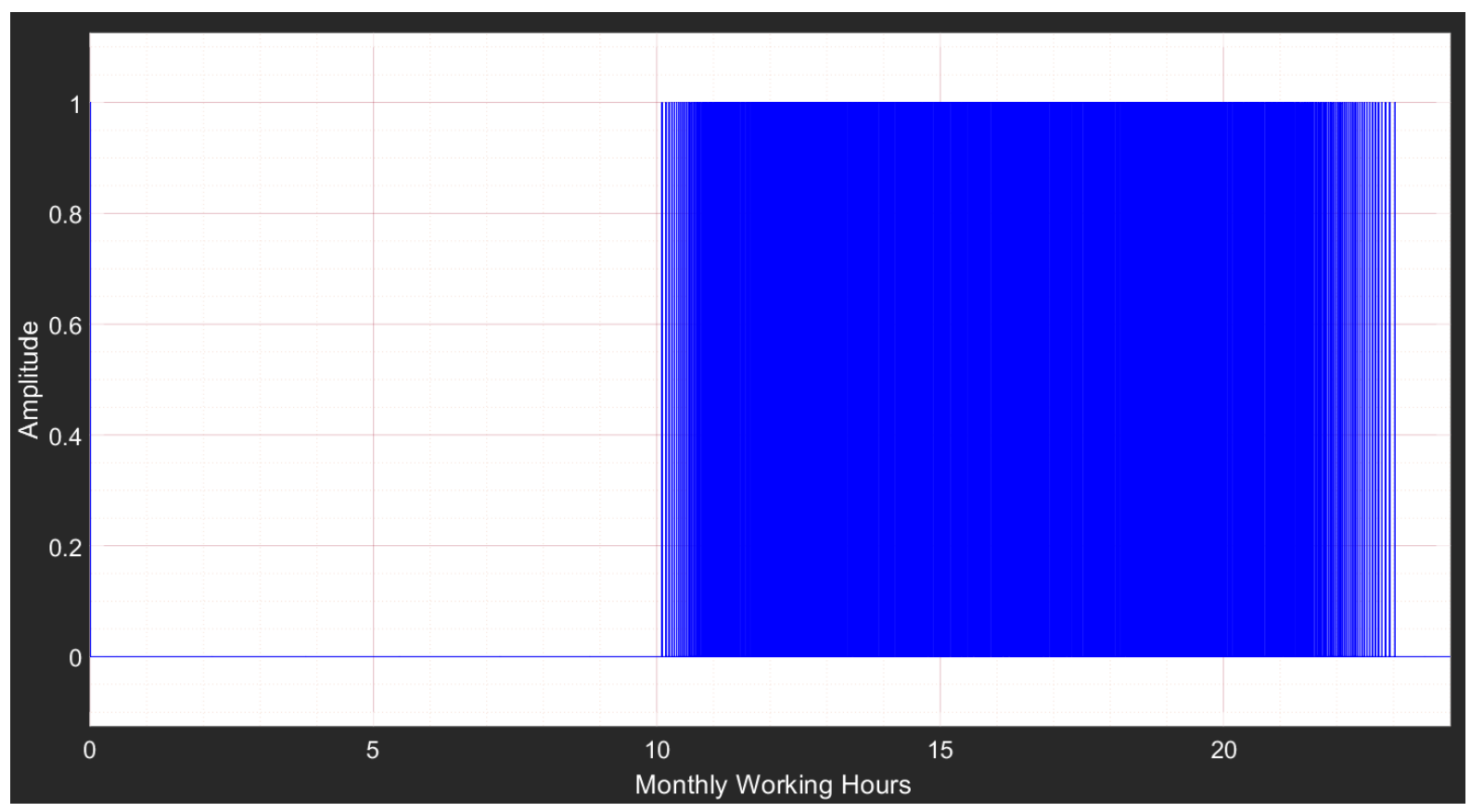

Figure 9. The control signal generated from the thermostat for $23{ }^{\circ} \mathrm{C}$ setpoint.

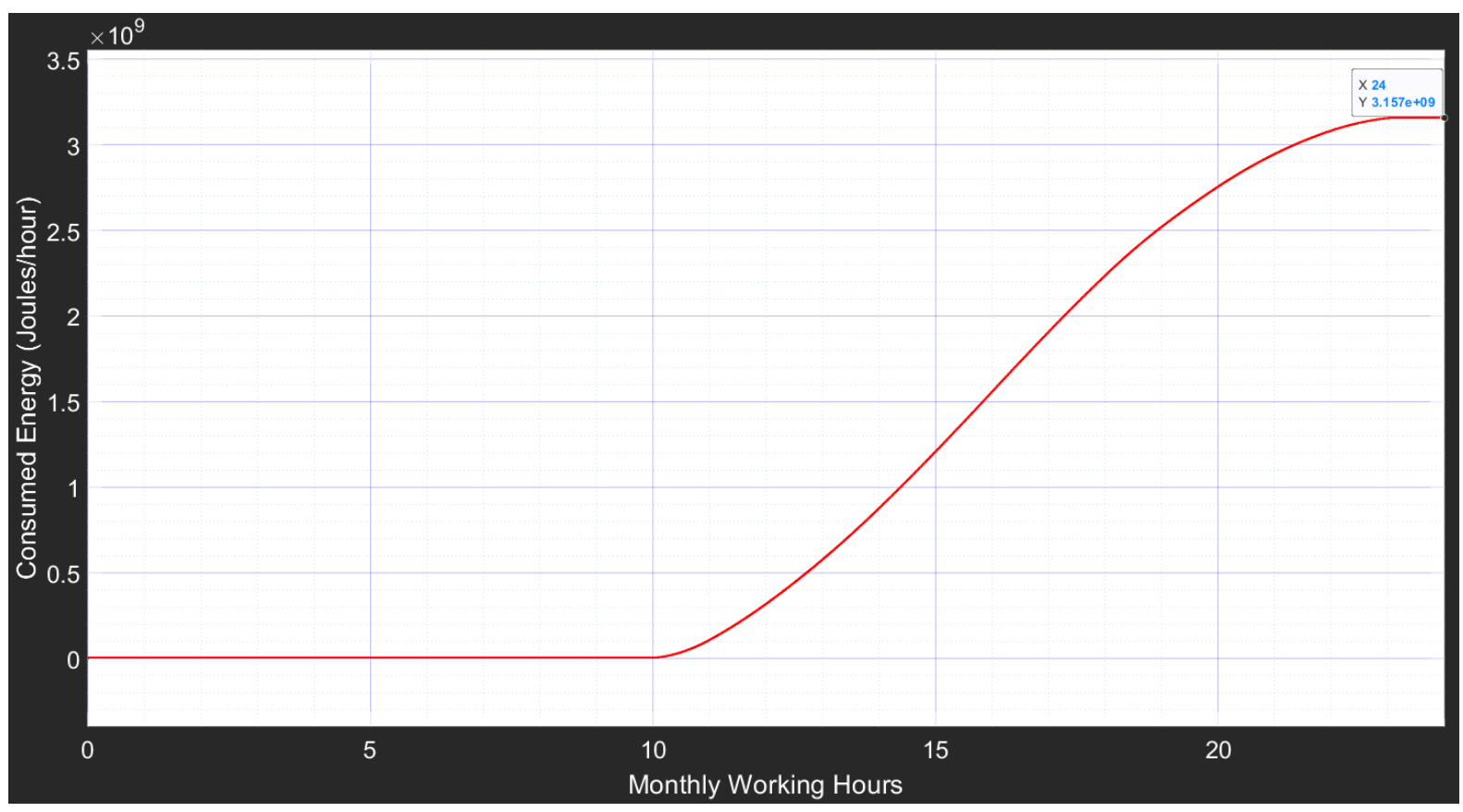

Figure 10. The monthly energy consumed to cool the building for $23{ }^{\circ} \mathrm{C}$ setpoint. 


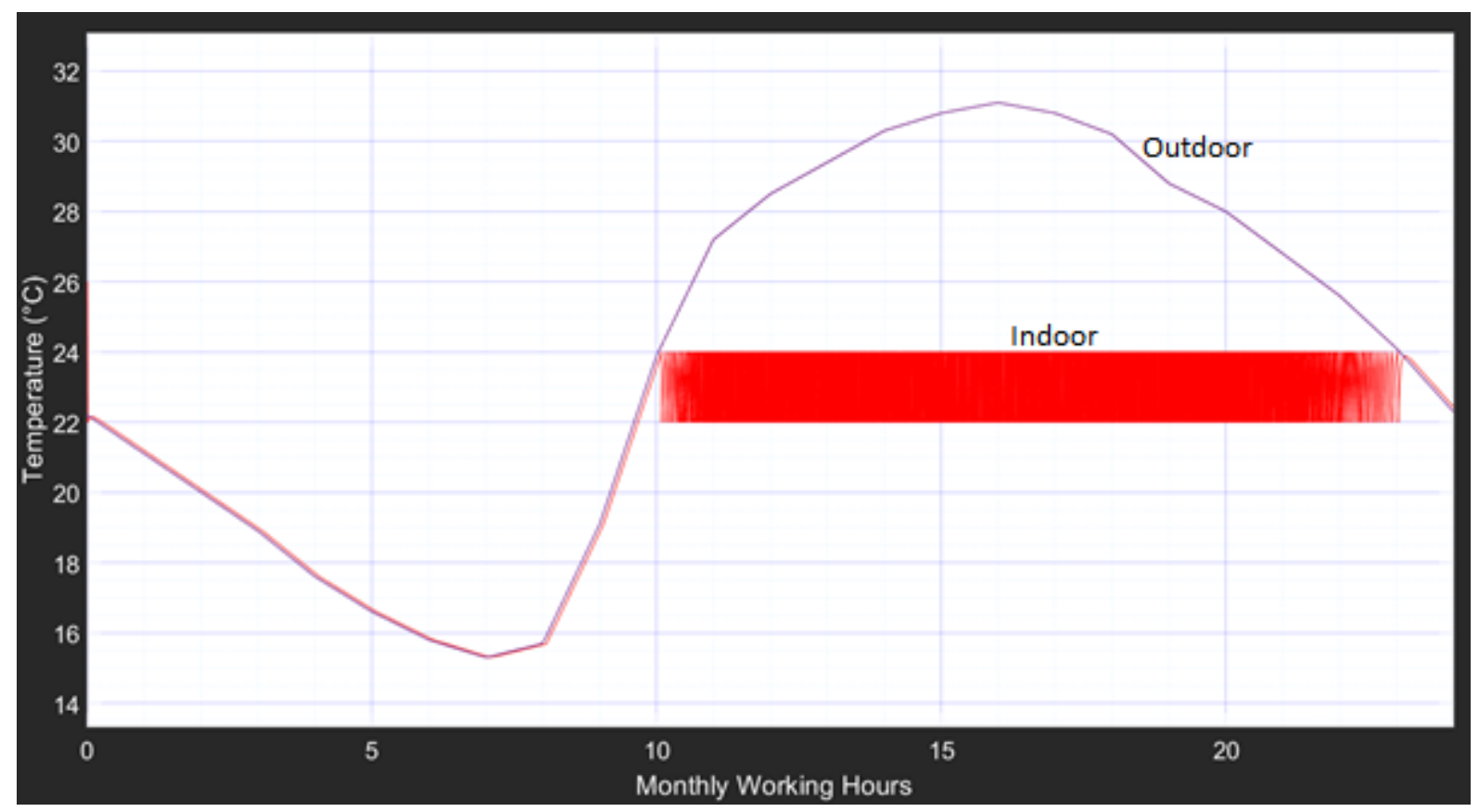

Figure 11. The indoor and outdoor temperature for $23^{\circ} \mathrm{C}$ setpoint.

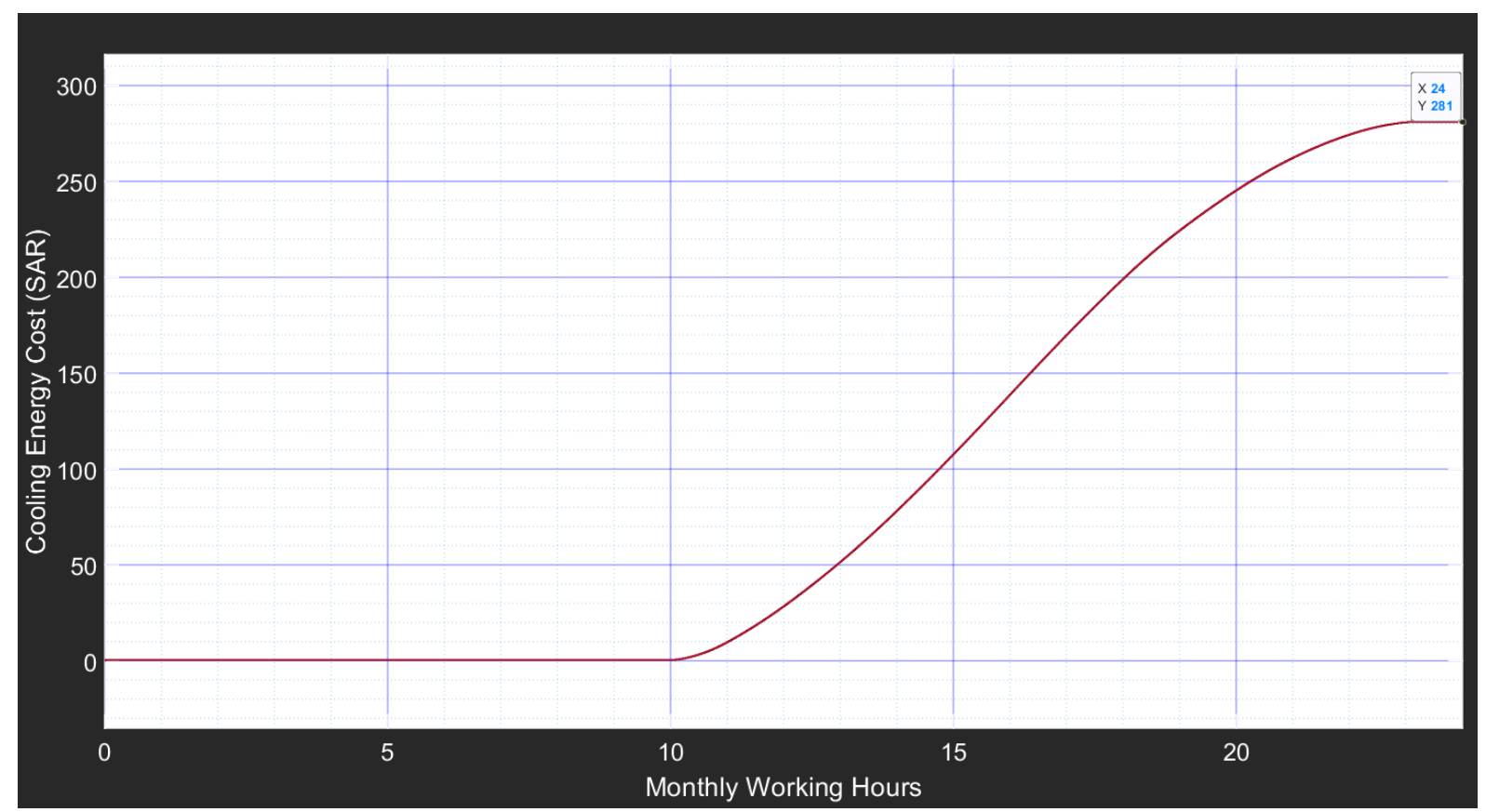

Figure 12. The monthly cost of cooling energy for $23^{\circ} \mathrm{C}$ setpoint. 


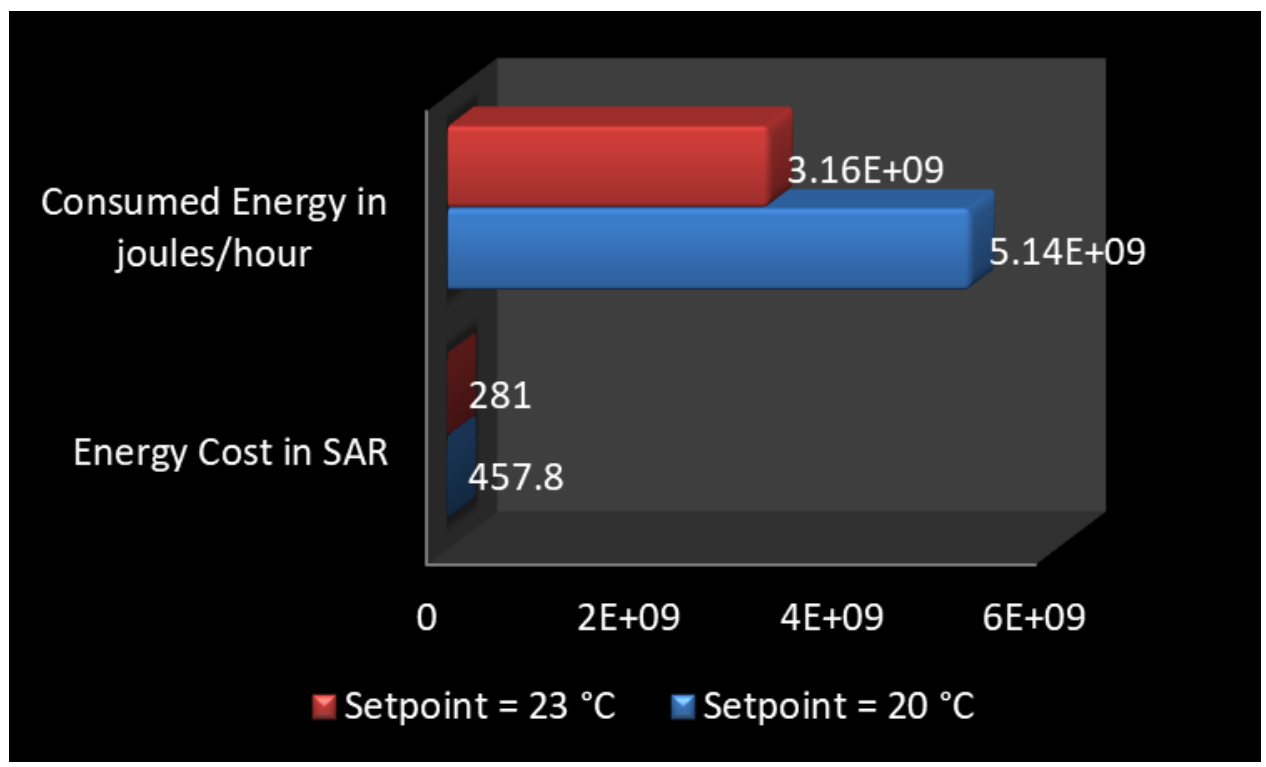

Figure 13. Comparing the monthly consumed energy and its cost for the two setpoints.

\section{CONCLUSION}

Energy consumption in buildings accounts for more than $50 \%$ of the total electrical energy consumption in KSA. The annual climate conditions, the types of materials used in the construction, and the lack of energy reduction culture among occupants contribute to this high energy demand. The main objective of this study was to identify and calculate the necessary variables for a building that can be used as input data in energy simulation tools and to examine the influence of applying energy rationalization measures on reducing the cooling energy consumption. A zonalmodelling approach was applied in this case study to simulate the heat and mass transfer in a university laboratory building to assess the effect of site environment and the internal heat loads on indoor temperatures. The paper also presented the result of increasing the setpoint temperature from $20^{\circ} \mathrm{C}$ to $23{ }^{\circ} \mathrm{C}$. This measure alone resulted in more than $61 \%$ reduction in the monthly energy cost for the building under study. Building owners can accomplish further cost savings by taking various steps together. Authors are now working on testing the effect of other energy rationalization measures.

\section{ACKNOWLEDGMENT}

The authors would like to express their gratitude to King Khalid University, Saudi Arabia, for funding this research under grant number 413 and for providing the necessary administrative and technical support. The first author also likes to extend his thanks to Sudan University of Science and Technology in Khartoum, Sudan. 


\section{REFERENCES}

Amara, F., Agbossou, K, Cardenas, A., Dubé, Y., \& Kelouwani, S. 2015. Comparison and simulation of building thermal models for effective energy management, smart grid and renewable energy. 2015, 6, 95112, Published Online April 2015 in SciRes. http://www.scirp.org/journal/sgre and http://dx.doi.org/10.4236/sgre.2015.64009 (accessed on 22 October 2019)

ANSI/ASHRAE 55-2017: Thermal Environmental Conditions for Human Occupancy

ASHRAE Handbook Committee. 2017. ASHRAE Handbook-Fundamentals. W. Stephen Comstock: 1791 Tullie Circle, Atlanta, GA 30329, USA, 2017

Bataineh, K., \& Alrabee, A. 2018. Improving the energy efficiency of the residential buildings in Jordan. Buildings 8, no. 7: 85 .

Body Surface Area. Available online: http://www-users.med.cornell.edu/ spon/picu/calc/bsacalc.htm (accessed on 20 August 2019)

Carlinia, M., Zillib, D., \& Allegrinia, E. 2015. Simulating building thermal behaviour: the case study of the school of the state forestry corp. ScienceDirect Energy Procedia 81 ( 2015 ) 55 - 63 69th Conference of the Italian Thermal Machines Engineering Association, ATI2014

Com3lab: The Compact Electronics Laboratory. Available online: http://www.hanmacco.com/images/_contents/file003/P1.pdf(accessed on 15 September 2019)

DELL INSPIRON N5110 Setup Guide. Available online: https://downloads.dell.com/manuals/allproducts/esuprt_laptop/esuprt_inspiron_laptop/inspiron-15r-n5110_setup\%20guide_en-us.pdf (accessed on 30 August 2019)

DELL OPTIPLEX 790 Technical Guide. Available online: https://i.dell.com/sites/doccontent/sharedcontent/data-sheets/en/Documents/optiplex-790-tech-guide.pdf (accessed on 30 August 2019)

Dubey, K., \& Dodonov, A. 2018. Mapping of existing technologies to enhance energy efficiency in buildings in the UNECE Region, joint task force on energy efficiency standards in buildings; United Nations Economic Commission for Europe: Geneva, Switzerland; Available online: https://www.unece.org/fileadmin/DAM/hlm/Meetings/ 2018/10_03_Geneva/1_Study_on_Mapping_of_EE_technologies_v2.pdf (accessed on 29 October 2020).

Foucquier, A., Robert, S., Suard, F., Stephan, L., \& Jay, A. 2013. State of the art in building modelling and energy performances prediction: A review. Renewable and Sustainable Energy Reviews Journal 2013, 23, $272-288$

General Authority for Statistics Electricity Energy Statistics-2018. Available online: https://www.stats.gov.sa/sites/default/files/hst_ltq_lkhrbyy___rby_0.pdf (accessed on 2 November 2020)

Hrvoje, K., \& Mihaela, T. 2017. Review of methods for buildings energy performance modelling. IOP Conf. Series: Materials Science and Engineering 245 (2017) 042049 doi:10.1088/1757-99X/245/4/042049

Kaynakli, O. 2012. Thermal insulation: A review of the economical and optimum thermal insulation thickness for building applications. Renewable and Sustainable Energy Reviews Journal 2012, 16, 415-425.

Krarti, M., Dubey, K., \& Howarth, N. 2019. Energy productivity analysis framework for buildings: a case study of GCC region. Energy, 167, 1251-1265. doi:10.1016/j.energy.2018.11.060

LAB-VOLT Company. Available online: https://www.labvolt.com (accessed on 5 November 2020) 
Lapusan, C., Balan, R., Hancu, O., \& Plesa, A. 2015. Development of a multi-room building thermodynamic model using simscape library. ScienceDirect Energy Procedia 85 (2016) 320 - 328 Sustainable Solutions for Energy and Environment, EENVIRO - YRC 2015, 18-20 November 2015, Bucharest, Romania

LISIN High-Pressure Exhaust Fan Model DVN-101 / DVN-121 Catalogue. Available online: http://ridonelectrical.com/index.php?route=product/product\&path=66\&product_id=58 (accessed on 15 August 2019)

Long-term Weather Forecast Abha, Saudi Arabia. Available online: https://www.weather-atlas.com/en/saudiarabia/abha-long-term-weather-forecast (accessed 25 October 2019)

LUCAS NUELLE Company. Available online: https://www.lucas-nuelle.us (accessed on 7 November 2020)

Mohelníková, J., Novotný, M., Mocová, P. 2020. Evaluation of school building energy performance and classroom indoor environment. Energies 13, no. 10: 2489.

Mooneghi, M. A., Kargarmoakhar, R., \& Chowdhury, A. G. 2015. Improving the thermal performance of concrete masonry blocks. Florida Civil Engineering Journal 2015, 1-10

Philips Fluorescent Lamp Data Sheet. Available online: https://www.lighting.philips.com/main/prof (accessed on 20 October 2019)

Residential Split Systems From $\mathbf{0 . 6}$ to 5 T. $\mathbf{R}$. Available online: http://www.aireclima.com/TRANE/pdfs/yellow/yellow.pdf (accessed on 15 September 2019)

Saudi Energy Efficiency Center Annual Report-2018. Available online: https://www.seec.gov.sa/sites/default/files/blog_files/annual-report-2018.pdf (accessed on 12 September 2019)

Shohan, A. A. A., \& Gadi, M. B. 2020. Evaluation of thermal and energy performance in mosque buildings for current situation (simulation study) in mountainous climate of Abha city. Sustainability 12, no. 10: 4014.

Sjösten, A., Olofsson, T., \& Golriz, M. 2013. Heating energy use simulation for residential buildings. Proceeding of the Eighth International IBPSA Conference Eindhoven, Netherland, August 11-14, 2003 pp 1221-1226.

Suszanowicz, D. 2017. Internal heat gain from different light sources in the building lighting systems. In E3S Web of Conferences, Proceedings of International Conference on Energy, Environment and Material Systems (EEMS2017), Polanica-Zdroj, Poland, September 2017, Wzorek, M. et al, EDP Sciences: DOI: $10.1051 / \mathrm{e} 3$ sconf/20171901024

Wonorahardjo, S., Sutjahja, I. S., Mardiyati, Y., Andoni, H., Thomas, D., Achsani, R. A., \& Steven, S. 2019. Characterizing thermal behavior of buildings and its effect on urban heat island in tropical areas. International Journal of Energy and Environmental Engineering https://doi.org/10.1007/s40095-019-00317-0

Yashen, L. 2012. Modeling the thermal dynamics of a single room in commercial buildings and fault detection, Master Of Science, The University Of Florida, USA, 2012 